\title{
Field investigation of the deterioration of flexible polymer modified pavements: A case study in northern New England
}

\author{
M. Elshaer \& C. Decarlo \\ US Army Corps of Engineers Engineering Research and Development Center, Cold Regions Research and \\ Engineering Laboratory, Hanover, USA
}

\begin{abstract}
The durability of flexible pavements in cold regions is a challenge due to the impact of environmental conditions such as extremely low temperatures and freeze-thaw cycling. In an attempt to tackle this issue, several asphalt modifiers have been evaluated as a potential solution to resist degradation and reduction of service life. Among these modifiers, polymer modification has a strong track record in improving the resistance of asphalt mixtures to various distresses typical in cold climates, both loading and environmental driven. The objective of this study is to investigate the structural deterioration of solid, pelletized polymer-modified asphalt pavement sections over the course of one year. Four test sections were constructed in Northern New Hampshire with different polymer dosage rates; control (with no polymer), $2.5 \%$ polymer, $5 \%$ polymer, and $7.5 \%$ polymer by weight of asphalt binder. To assess the structural capacity and performance of the pavement sections, Falling weight deflectometer (FWD) testing was conducted at each test over the course of one year after construction. A comprehensive analysis was performed to scrutinize the measured FWD deflection data for each test section. Backcalculation analysis was conducted to estimate the stiffness of pavement layers and track the asphalt layer's structural deterioration over time for each pavement section. The field investigation results showed that the modified polymer sections exhibited less degradation over time compared to the control section. In addition, the results suggested that polymer modification to the AC layer results in structural benefits to the pavement structure.
\end{abstract}

Keywords: Polymer Modification, Flexible Pavement, FWD, Backcalculation, Cold Regions, Deterioration

\section{INTRODUCTION}

Asphalt pavements in cold climates experience a significant amount of distress, including both traffic and environment driven, throughout their service lives. Historically, many transportation agencies have sought to improve the mechanical performance of their asphalt mixtures through the use of additives. Among the many additives used, polymer modification is one of the most popular forms of additives used in modern asphalt construction due to its ability to improve the overall materials' high-temperature properties without compromising lowtemperature behavior. Polymer modification is beneficial in cold climates as it allows the use of a soft base binder to prevent thermal cracking while maintaining significant amounts of stiffness at high temperatures to reduce susceptibility to rutting.

Multiple studies have documented the performance benefits of using polymer modification (Bates and Worch 1987, Bahia et al 1997, Roque et al 2004). Newman (2003) investigated the 
effectiveness of using styrene-butadiene-styrene and styrene-butadiene-rubber (SBS and SBR) in airfield mixtures. Results from bending beam fatigue testing indicated a significant increase in fatigue cycles to failure for both polymers. Additionally, Isaacson and Zheng (1998) investigated five different polymer-modified materials in three asphalt mix designs using the thermal stress restrained specimen test. Results showed that while the effectiveness of the additives heavily depended on the specific polymer, aging levels, and mixture volumetrics, all of the polymer additives improved the mixture's resistance to low-temperature thermal cracking.

While polymer additives have been shown to clearly improve asphalt mixture performance, they are not without drawbacks, especially when considered in construction inexpedient and remote environments. One of the most prominent challenges is storage and handling of the material, where specialized heating and storage tanks are required. If improperly handled, the polymer network in the asphalt binder will be disturbed, significantly reducing the performance gains of the material (Wegan 2001). While these are commonly available in areas with routine asphalt construction, this equipment is typically not available in remote and expedient environments where the use of temporary, smallscale production plants are more common.

One potential way to address this problem is the use of pelletized polymer additives (Iterchimica 2008). Pelletized polymers are added in as solids directly into the pugmill or mixing drum, requiring minimal modifications to existing plant architecture. Being able to store the additives in dry, bulk form allows them to always be available and ready for quick deployment in remote and expedient construction. While laboratory results with pelletized polymer-modified mixtures have shown promising results (Azam et al 2019), there is a lack of field studies that have been conducted analyzing the performance of the material, particularly in cold climates. Therefore, this pelletized polymer is needed to be investigated in the field to determine the performance of polymer-modified mixes over time.

With this knowledge gap in mind, the overall objectives of this study are as follows:

- Construct field sections of pelletized polymer modified asphalt in a cold climate and monitor the performance of those sections over time.

- Evaluate the effect of pelletized polymer dosage on-field performance.

- Gain an understanding of the deterioration of pelletized polymer modified mixtures over the course of a winter season as compared to conventional asphalt mixtures.

\section{MATERIALS, CONSTRUCTION, AND TESTING PROGRAM}

\subsection{Materials}

To satisfy the objectives of this study, four asphalt mixtures were produced and placed in the field. For this study, a virgin, 12.5mm NMAS, dense-graded Superpave surface mixture with a PG64-22 binder was selected as the control mixture. This control mixture was then modified with three levels of the solid polymer by weight of asphalt binder: $2.5 \%, 5.0 \%$, and $7.5 \%$ for a total of four asphalt mixtures. The four mixtures were produced at a batch plant using a dry mix process where the pelletized polymer additive was introduced into the pugmill with the heated aggregates per the additive manufacturers' recommendations. It should be noted that this is in contrast to typical polymer modification where the additives are in the asphalt binder. The pelletized polymers were allowed to mix with aggregate heated to $170-180^{\circ} \mathrm{C}$ for 30 seconds in the pugmill before the asphalt binder was introduced into the mixture where another 30 seconds of mixing was allowed to thoroughly coat the aggregates. Table 1 shows the design gradation and volumetrics of the control mixture design as well as the gradation and volumetrics of the as-produced mixtures that were used for field construction and testing. ASTM D2172 and ASTM D6925 were followed to determine the gradation and volumetric properties of the mixtures. 
Table 1. Production quality control results.

\begin{tabular}{|c|c|c|c|c|c|c|}
\hline \multicolumn{2}{|l|}{ Mixture } & \multirow{2}{*}{$\begin{array}{l}\text { Design } \\
\text { Gradation }\end{array}$} & \multirow{2}{*}{$\begin{array}{l}\text { Control } \\
\text { QC }^{\mathrm{a}} \\
\text { Test } \\
100.0\end{array}$} & \multirow{2}{*}{$\begin{array}{l}2.5 \% \\
\text { Polymer } \\
\text { QC Test } \\
100.0\end{array}$} & \multirow{2}{*}{$\begin{array}{l}5.0 \% \\
\text { Polymer } \\
\text { QC Test } \\
100.0\end{array}$} & \multirow{2}{*}{$\begin{array}{l}7.5 \% \\
\text { Polymer } \\
\text { QC Test }\end{array}$} \\
\hline Percent Passing & $3 / 4 \mathrm{in.} / 19.0 \mathrm{~mm}$ & & & & & \\
\hline \multirow[t]{9}{*}{$(\%)$} & $1 / 2 \mathrm{in} . / 12.5 \mathrm{~mm}$ & 96.8 & 95.8 & 96.0 & 95.9 & 96.0 \\
\hline & $3 / 8 \mathrm{in} . / 9.5 \mathrm{~mm}$ & 83.6 & 84.2 & 83.6 & 85.9 & 85.3 \\
\hline & \#4/4.75 mm & 55.1 & 52.1 & 50.4 & 54.6 & 50.1 \\
\hline & $\# 8 / 2.36 \mathrm{~mm}$ & 35.0 & 36.5 & 33.6 & 39.8 & 34.8 \\
\hline & $\# 16 / 1.18 \mathrm{~mm}$ & 24.4 & 27.6 & 24.8 & 30.1 & 25.5 \\
\hline & \#30/0.60 mm & 17.8 & 19.0 & 17.1 & 19.9 & 17.0 \\
\hline & \#50/0.30 mm & 10.1 & 10.1 & 9.1 & 9.6 & 9.7 \\
\hline & \#100/0.15 mm & 6.0 & 4.8 & 4.3 & 3.8 & 5.0 \\
\hline & $\# 200 / 0.075 \mathrm{~mm}$ & 3.0 & 2.8 & 2.4 & 2.4 & 3.0 \\
\hline \multicolumn{2}{|c|}{ Binder Content $(\%)$} & 5.80 & 5.79 & 5.92 & 5.89 & 6.12 \\
\hline \multicolumn{2}{|c|}{ Air Voids at 50 Gyrations (\%) } & 4.0 & 4.3 & 3.3 & 4.2 & 3.2 \\
\hline \multicolumn{2}{|c|}{ Maximum Specific Gravity } & 2.492 & 2.497 & 2.482 & 2.487 & 2.485 \\
\hline \multicolumn{2}{|c|}{ Voids in Mineral Aggregate $(\%)^{\mathrm{b}}$} & 14.5 & 14.8 & 14.6 & 15 & 14.6 \\
\hline \multicolumn{2}{|c|}{ Voids Filled with Asphalt (\%) ${ }^{\mathrm{c}}$} & 73.8 & 70.9 & 77.2 & 72.4 & 77.8 \\
\hline \multicolumn{2}{|c|}{ Dust-to-Binder Ratio } & 0.68 & 0.63 & 0.51 & 0.52 & 0.63 \\
\hline
\end{tabular}

a Quality Control.

b Minimum Superpave voids in mineral aggregate for $12.5 \mathrm{~mm}$ NMAS mix is 14.0.

c Allowable Superpave voids filled with asphalt range for $12.5 \mathrm{~mm}$ NMAS mix is $70-80$.

\subsection{Field sections}

As part of this study, four field test sections were constructed to evaluate the polymermodified mixture's performance in a cold climate. The site chosen for this work was a lowvolume road serving mostly residential and some truck traffic in northern New England, where the average winter low temperature is $-27^{\circ} \mathrm{C}$ with $30-60$ annual freeze-thaw cycles. The test sections were designed as a $50 \mathrm{~mm}$ overlay over an existing pavement. The existing pavement is a conventional asphalt pavement (12.5 NMAS with PG64-22 binder) with a $75 \mathrm{~mm}$ asphalt surface and $200 \mathrm{~mm}$ full-depth reclamation (FDR) A-1-a base material, all of which is constructed on a A-2-4 silty sand subgrade. The most prominent distress in the existing pavement was moderate severity transverse cracks spaced approximately every $9 \mathrm{~m}$.

The test sections used in this study were laid out as shown in Figure 1. Four sections were set up as pairs in the adjacent lane of the low-volume road. The target length for each test section was set as 152.4 meters with 15-meter transition zones at the beginning, end, and between the test sections to facilitate paving operations and allow smooth transitions between test sections. Prior to paving of the test sections, the existing transverse cracks were sealed

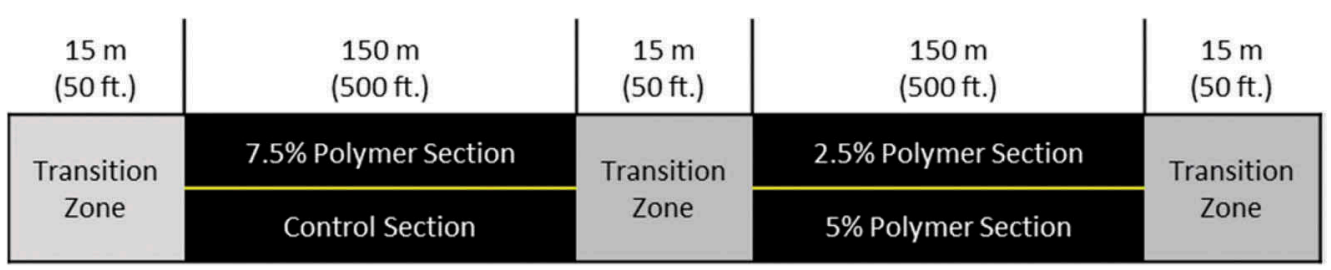

Figure 1. Test sections layout. 
with a mastic-based crack sealant and a RS-1 rapid setting emulsion tack coat was applied at a residual rate of $0.22 \mathrm{~L} / \mathrm{m}^{2}$.

During the construction of the test sections, the density of the overlay layer was monitored using an electronic density guage. After construction, cores were taken to determine the asbuilt thickness of the overlay sections and to verify the density measurements. The final densities for the four sections were $94 \%$, and the average overlay thickness were found to be $53 \mathrm{~mm}$ for the control section, 51 for $5 \%$ polymer section, $42 \mathrm{~mm}$ for the $2.5 \%$ polymer section, and $43 \mathrm{~mm}$ for the $7.5 \%$ polymer section.

In general, the construction of the test sections was without significant challenges. No differences were noticed in paving and compacting the modified layers with respect to the control. One observation worth noting was after the breakdown rolling, small check cracks were observed in all four sections. Although inconsistent in their amount and location, check cracking was observed in all four sections. After finish rolling and initial trafficking, the check cracking was not visible and no obvious deterioration due to the check cracking has been observed to this point.

\subsection{Testing program}

The test sections were visited periodically after the construction in June 2019 to assess the field condition of the control overlay section and three-solid-polymer-modified overlay sections. The field investigations of the four asphalt overlay sections involved the assessment of the structural capacity using Falling Weight Deflectometer (FWD) test at different locations. A Dynatest 8000 FWD setup with a $300 \mathrm{~mm}$ diameter loading plate was used to measure the deflection of the pavement surface on the mid lane and outer wheel path in the direction of travel following LTPP protocol (Schmalzer 2006). FWD tests were conducted every $7 \mathrm{~m}$ for about $152 \mathrm{~m}$ in length for all four sections. FWD tests were conducted three times; 2 months, 5 months, and 12 months after construction at each section to investigate the structural integrity and deterioration over time.

To enhance the interpretation of FWD deflection, the impact of temperature, moisture content, traffic loads, and pavement structure were taken into account. The subgrade layer was investigated by collecting soil samples using a hand auger and sent to the laboratory to determine the soil material properties and the soil moisture content during the time of conducting the FWD test. The air and surface temperatures were measured through the sensors installed in the FWD device. Four holes were drilled at different depths $(17 \mathrm{~mm}, 25 \mathrm{~mm}, 50 \mathrm{~mm}$, and $76 \mathrm{~mm}$ from the pavement surface) and filled with oil to measure the asphalt gradient temperature every 30 minutes during the time of conducting the FWD test. To evaluate the structural capacity of four overlay sections and determine the deteriorations over time, comprehensive methods were carried out as follows:

\subsection{Maximum deflection $\left(D_{0}\right)$}

The maximum pavement deflection at the load plate reflects the strength of the overall pavement structure. The maximum deflections for each test point were normalized to $40 \mathrm{kN}$ and then corrected to a reference temperature of $20^{\circ} \mathrm{C}$, (Kim et al. 1995), using the measured middepth asphalt temperature:

$$
D_{68}=D_{T} \times\left[10^{\propto(68-T)}\right]
$$

where $D_{68}=$ the adjusted deflection (in.) to the reference temperature of $20^{\circ} \mathrm{C}\left(68^{\circ} \mathrm{F}\right), D_{T}=$ the deflection (in.) measured at temperature $T\left({ }^{\circ} \mathrm{F}\right), \alpha=3.67 \times 10^{-4} \times t^{1.4635}$ for wheelpaths, $t=$ the thickness of the AC layer (in.), and $T=$ the AC layer mid-depth temperature $\left({ }^{\circ} \mathrm{F}\right.$ ) at the time of FWD testing. 


\subsection{Backcalculation analysis}

The FWD deflection values were backcalculated using Evaluation of Layer Moduli and Overlay Design (ELMOD) software to determine the stiffness of the pavement layers. ELMOD performs layer elastic analysis to iteratively adjust the seed modulus for each layer to match the predicted and measured deflections within some tolerable error.

To start the backcalclation analysis, pavement layer thickness and seed moduli of pavement layers should be defined. The thickness of the pavement layers of four sections was determined from the field cores conducted during the construction of the four sections. The asphalt layer was treated in the backcalculation analysis as two individual layers; the top layer is a thin asphalt overlay with a seed moduli of $3447 \mathrm{MPa}$ at $20^{\circ} \mathrm{C}$ determined based on the dynamic modulus master curve conducted in the laboratory. The second layer is the old existing asphalt layer with a seed moduli of $1034 \mathrm{MPa}$ at $20^{\circ} \mathrm{C}$ and treated as a fixed layer in the backcalculation analysis (Pierce et al. 2017). This gives a better insight into the comparison of the stiffness of the overlay layer among the four sections. Several attempts were made to minimize the associated error resulted from the thin overlay in the backcalculated analysis to $1-3 \%$. For the base layer, the seed modulus value for the FDR layer was assumed to be $413 \mathrm{MPa}$ (AASHTO 2008). For the subgrade layer, the seed modulus of the subgrade at the time of the FWD measurements was determined from the measured moisture content. The soil samples from four depths $(400,475,550$, and $600 \mathrm{~mm}$ from the pavement surface) were collected each time during the FWD test and sent to the laboratory to measure the moisture contents following ASTM D (2019a) 2216-19. Witczak's equation, presented in equation (2), was used to determine the resilient modulus at the time of the FWD measurements based on the measured moisture content. This resilient modulus value was considered to be the seed modulus value of the subgrade in the backcalculation analysis

$$
\log \frac{M r}{M r_{\text {opt }}}=a+\frac{b-a}{1+\exp \left[\ln \frac{-b}{a}+k_{m}\left(S-S_{\text {opt }}\right)\right]}
$$

where $M r=$ the resilient modulus at any degree of saturation; $M r / M r_{o p t}=$ the resilient modulus ratio; $M r_{\text {opt }}=$ the resilient modulus at a reference condition; $a=$ the minimum of $\log M r / M r_{o p t}$; $b=$ the maximum of $\log M r / M r_{o p t} ; k_{m}=$ the regression parameter, and $S-S_{\text {opt }}=$ the variation in degree of saturation expressed in decimals.

The backcalculation analysis utilized the FWD deflections measured in the outer wheel path at the last drop of the $40 \mathrm{kN}$ load. The outer wheel path was selected because pavement distress usually occurs in the wheel path. The measured mid-depth temperature of the asphalt overlay layer was considered as the effective temperature to represent the asphalt layer temperature at the time of the FWD measurement. The backcalculated moduli of the asphalt overlay layer were then corrected to the standard temperature of $20^{\circ} \mathrm{C}$ using the asphalt temperature adjustment factor (ATAF) following the model presented in Lukanen et al. 2000. The first time of FWD measurement was considered to be the reference point to which the overlay backaclualted moduli ratio was calculated. The ratio of the backcalculated moduli of the overlay layer at different times to the first time of measurements was computed to investigate the stiffness degradation over time.

\subsection{Modified Structural Number (SNC)}

The structural number represents the effective structural strength of the existing pavement. The modified structural number (SNC) based on the FWD maximum deflection $\left(D_{0}\right)$ for asphalt pavement (equation 3) was calculated to determine the structural capacity of four sections. SNC was calculated based on the normalized maximum deflection to $40 \mathrm{kN}$ and corrected to a reference temperature of $20^{\circ} \mathrm{C}$ for reasonable comparison among four sections: 


$$
\mathrm{SNC}=3.2 \times D_{0}^{-0.63}
$$

where $\mathrm{SNC}=$ the modified structural number and $D_{0}=$ the maximum deflection $(\mathrm{mm})$.

The ratio of the SNC at different times to the first time of measurements was computed to investigate the structural capacity deterioration over time.

\section{RESULTS AND DISCUSSIONS}

\subsection{Maximum deflection $\left(D_{0}\right)$}

Figure 2 shows the average normalized maximum deflection to $40 \mathrm{kN}$ load and corrected to $20^{\circ} \mathrm{C}$ with the associated standard deviation in the outer wheel path for each section at different time of measurements. As the figure shows, the sections with polymer-modified asphalt showed relatively lower deflection values compared to the control section at each time of measurements. This suggests that the polymer slightly improved the structural capacity of the sections regardless of the dosage rate. This figure also depicts that the polymer dosage had a smaller impact on the deflection values. The section modified with $5 \%$ polymer showed relatively the lowest deflection values at each time of measurement.

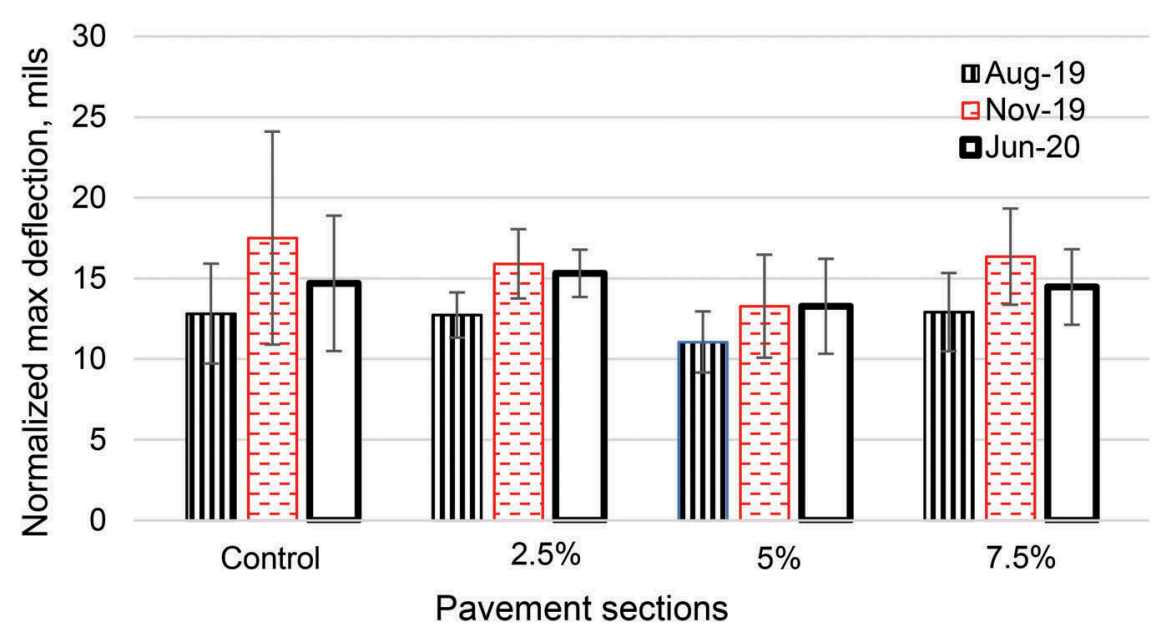

Figure 2. Normalized maximum deflection for all pavement sections.

Figure 3 shows the ratio of normalized maximum deflection at different time after construction to normalized maximum deflection right after construction. The largest ratio was for the control section, where there is a $15-37 \%$ increase in the deflection after one year of construction. On the other hand, there is an average of $12-20 \%$ increase in the deflection after one year of construction for the polymer modified sections. The polymer dosage had a slight impact on the rate of change in deflection. This figure also depicts that the percent of change in deflection for the control is higher than those in polymer-modified sections. This indicates that the pelletized-polymers could have the potential to lower the degree of deterioration the pavement will experience over time. 


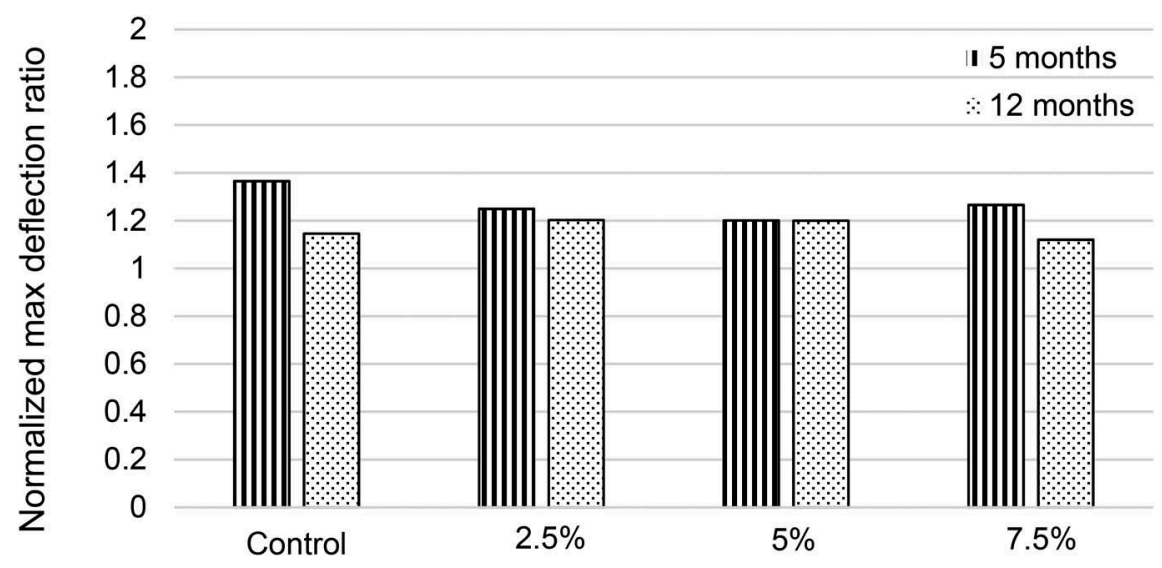

Pavement Sections

Figure 3. Ratio of seasonal normalized maximum deflection for all pavement sections.

\subsection{Backcalculation analysis}

Figure 4 shows the ratio of the AC overlay moduli at a different time of measurements to AC overlay moduli right after construction. This figure illustrates that the rate of deterioration in the control section was the greatest among all other sections after 5 months of construction, where the control section showed a $70 \%$ decrease in the AC overlay moduli. On the other hand, the sections modified with polymer shows a different trend. As the figure shows, the polymer dosage had a significant impact on the rate of deterioration. The section that was modified with $2.5 \%$ and $7.5 \%$ polymer exhibited no deterioration in the AC overlay moduli. The sections that were modified with $5 \%$ showed a $15 \%$ drop in the AC overlay moduli. After one winter freeze-thaw season and one year after construction, $5 \%$ and $7.5 \%$ polymer sections showed similar performance which there is a $35 \%$ decrease in the AC overlay moduli while the control and $2.5 \%$ polymer sections showed no change in the AC overlay moduli. This indicates that the section modified with $2.5 \%$ polymer may lower the rate of deterioration over time. These mixed results in the figure could be due to the viscoelastic behavior of the asphalt overlay layer, where the backcalculation approach presented in this study wasn't able to distinguish the accurate influence on the thin AC overlay. This also could be due to the contribution of the high moisture content accumulated in the base layer after the spring-thaw time, which adversely impacted the stiffness of remaining layers.

\subsection{Modified Structural Number (SNC)}

Figure 5 shows the ratio of the modified structural number (SNC) for all four overlay sections over one year. The results show that there is a slight impact from the pavement section on the change in the SNC. The results also revealed that the dosage of the polymer has a smaller impact on change in the structural capacity of pavements. A 9-18\% reduction of the structural capacity for control section and $7-13 \%$ reduction for polymer sections are observed over one year after construction. 


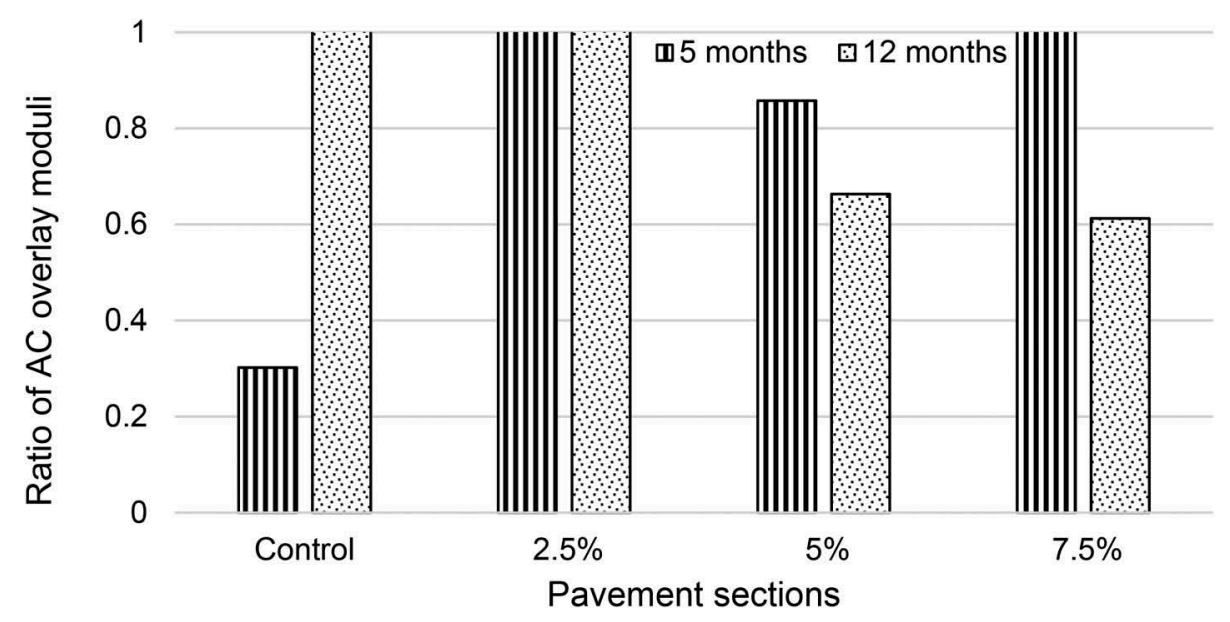

Figure 4. Ratio of seasonal AC overlay moduli for all pavement sections.

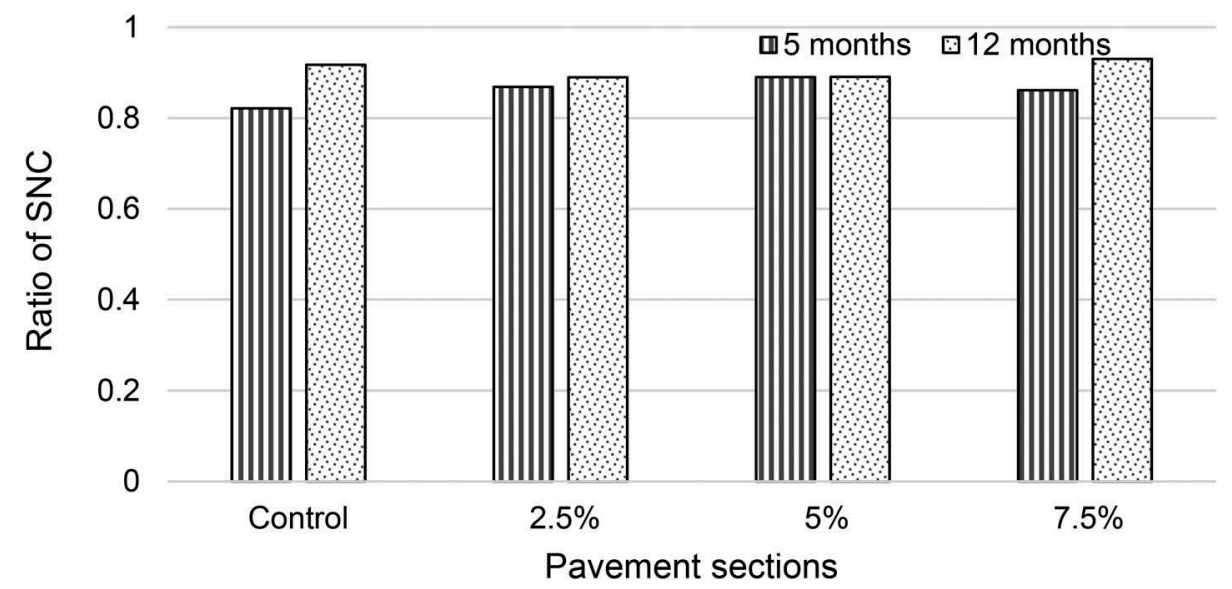

Figure 5. Ratio of seasonal SNC for all pavement sections.

\section{CONCLUSION}

A control section and three pelletize-polymer modified sections were constructed in northern New England to better understand the deterioration rate of pelletized-polymer-modified sections over time. The asphalt mixture for the control section was produced in the plant using a Superpave mix design with a PG 64-22 binder. The asphalt mixtures for the three other sections were modified using pelletize polymer, which was added during the plant production using the dry mix procedure. No issue was observed during the production and construction of solid polymer-modified sections. FWD test was conducted shortly and periodically over one year after construction on the control and three polymer sections to preliminary investigate the structural capacity of these four sections and determine the deterioration rate over one year of service (two summer seasons and one winter season). Three different analysis methods were conducted to better analyze the FWD deflection data. The findings and conclusions can be summarized as follows: 
- The results from the maximum deflection showed that the polymer-modified sections showed less degradation over one year of service. It is concluded that the addition of polymer may slightly improve the structural capacity of the pavement structure.

- The backcalcualtion analysis showed that the climate season and the dosage of polymer had an impact on stiffness degradation over time. Before the winter season, the control section exhibited the largest degradation after 5 months of service among all other polymer sections. The sections modified with $2.5 \%$ and $7.5 \%$ polymer exhibited no degradation and a slight degradation was observed from $5 \%$ polymer section. After one winter season, the control and $2.5 \%$ polymer sections exhibited no degradation. Though, $2.5 \%$ and $5 \%$ polymer sections exhibited degradation of almost $35 \%$. These mixed results between before and after winter season could be due to the seasonal variations of unbound layers' moisture and the limitation of the backcalculation analysis to differentiate the impact of AC overlay.

- The structural strength analysis using the structural number showed that there is a similar degradation over time among control and three polymer sections. The rate of polymer dosage had a smaller impact on the change in the structural capacity over time.

Therefore, it can be concluded that this type of pelletized polymer has the potential to improve the structural capacity and lower the degradation the pavement will experience over time. However, further extensive field investigation is still needed over time to display a definitive conclusion about this polymer type.

\section{ACKNOWLEDGEMENTS}

The use of trade, product, or firm names in this document is for descriptive purposes only and does not imply endorsement by the U.S. Government. The tests described and the resulting data presented herein, unless otherwise noted, are based upon work supported by the US Army ERDC under PE 0603119a, Project T26 "Military Engineering Applied Research", Task "Innovative Construction Materials for the Arctic". Permission was granted by the Director, Cold Regions Research and Engineering Laboratory to publish this information. This project was supported in part by an appointment to the Research Participation Program at the US Army Cold Regions Research and Engineering Laboratory (CRREL), US Army ERDC, U.S. Department of Defense (DoD), administered by the Oak Ridge Institute for Science and Education through an interagency agreement between the U.S. Department of Energy and DoD. The findings of this paper are not to be construed as an official Department of the Army position unless so designated by other authorized documents.

\section{REFERENCES}

Azam, A. M., S. M. El-Badawy, and R. M. Alabasse. 2019. "Evaluation of Asphalt Mixtures Modified with Polymer and Wax." Innovative Infrastructure Solutions 4 (1): 43.

Bates R, Worch R. Engineering Brief No. 39, Styrene-butadiene rubber latex modified asphalt. Federal Aviation Administration, Washington, DC, 1987.

H.U. Bahia, D. Perdomo, P. Turner. Applicability of Superpave binder testing protocols to modified binders. Transportation Research Record, 1586 (1997), pp. 16-23.

Iterchimica 2008. Road and Airfield uses of SUPERPLAST Modified Hot mix Asphalt.

Isacsson, U., and H. Zeng. 1998. Low-Temperature Cracking of Polymer-Modified Asphalt. Materials and Structures 31 (1): 58-63.

Kim, Y. R., B. O. Hibbs, and Y. C. Lee. 1995. "Temperature Correction of Deflections and Backcalculated Asphalt Concrete Moduli." Transportation Research Record 1473, 55-62. Washington, DC: Transportation Research Board, National Research Council.

Lukanen, E. O., R. Stubstad, and R. Briggs. 2000. Temperature Predictions and Adjustment Factors for Asphalt Pavement. FHWA-RD-98-085. McLean, VA: Federal Highway Administration.

Newman, J. K. 2003. "Flexural Beam Fatigue Properties of Airfield Asphalt Mixtures Containing Styrene-Butadiene Based Polymer Modifiers." In Proceedings of the Sixth International RILEM Symposium on Performance Testing and Evaluation of Bituminous Materials, 357-363. Bagneux, France: RILEM Publications SARL. 
Pierce, L. M., J. E. Bruinsma, K. D. Smith, M. J. Wade, K. Chatti, and J. Vandenbossche. 2017. Using Falling Weight Deflectometer Data with Mechanistic-Empirical Design and Analysis, Volume III: Guidelines for Deflection Testing, Analysis, and Interpretation. FHWA-HRT-16-011. McLean, VA: U.S. Federal Highway Administration.

Roque R, Birgisson B, Tia M, Kim B, Cui Z. Guidelines for the use of modifiers in Superpave mixtures: Executive summary and volume 1 of 3 volumes: Evaluation of SBS modifier. State Job 99052793. Florida Department of Transportation, Tallahassee, FL, 2004.

Schmalzer, P. N. 2006. Long-Term Pavement Performance Program Manual for Falling Weight Deflectometer Measurements. FHWA-HRT-06-132. McLean, VA: U.S. Federal Highway Administration, Office of Infrastructure Research and Development.

Wegan, V. 2001. Effect of Design Parameters on Polymer Modified Bituminous Mixtures. Copenhagen, Denmark: Danish Road Directorate. 